\title{
Impact of Face-to-Face Teaching in Addition to Electronic Learning on Personal Protective Equipment Doffing Proficiency in Student Paramedics: Protocol for a Randomized Controlled Trial
}

Loric Stuby ${ }^{1}$, CAS; Ludivine Currat ${ }^{2}$; Birgit Gartner ${ }^{3}$, MD; Mathieu Mayoraz ${ }^{1,4}$; Stephan Harbarth ${ }^{5}$, MD, MSc; Laurent Suppan $^{3}, \mathrm{MD} ;$ Mélanie Suppan ${ }^{6}, \mathrm{MD}$

\footnotetext{
${ }^{1}$ Emergency Medical Services, Genève TEAM Ambulances, Geneva, Switzerland

${ }^{2}$ ESAMB - École Supérieure de Soins Ambulanciers, College of Higher Education in Ambulance Care, Geneva, Switzerland

${ }^{3}$ Division of Emergency Medicine, Department of Anesthesiology, Clinical Pharmacology, Intensive Care and Emergency Medicine, University of Geneva Hospitals and Faculty of Medicine, Geneva, Switzerland

${ }^{4}$ MEDI - Center for Medical Education, College of Higher Education in Ambulance Care, Bern, Switzerland

${ }^{5}$ Infection Control Program and WHO Collaborating Centre on Patient Safety, University of Geneva Hospitals and Faculty of Medicine, Geneva, Switzerland

${ }^{6}$ Division of Anesthesiology, Department of Anesthesiology, Clinical Pharmacology, Intensive Care and Emergency Medicine, University of Geneva Hospitals and Faculty of Medicine, Geneva, Switzerland
}

\section{Corresponding Author:}

Loric Stuby, CAS

Emergency Medical Services

Genève TEAM Ambulances

Rue Docteur-Alfred-Vincent 18

Geneva, 1201

Switzerland

Phone: 41228001212

Email: 1.stuby@gt-ambulances.ch

\section{Abstract}

Background: The COVID-19 pandemic has brought attention to the importance of correctly using personal protective equipment (PPE). Doffing is a critical phase that increases the risk of contamination of health care workers. Although a gamified electronic learning (e-learning) module has been shown to increase the adequate choice of PPE among prehospital personnel, it failed to enhance knowledge regarding donning and doffing sequences. Adding other training modalities such as face-to-face training to these e-learning tools is therefore necessary to increase prehospital staff proficiency and thus help reduce the risk of contamination.

Objective: The aim of this study is to assess the impact of the Peyton 4-step approach in addition to a gamified e-learning module for teaching the PPE doffing sequence to first-year paramedic students.

Methods: Participants will first follow a gamified e-learning module before being randomized into one of two groups. In the control group, participants will be asked to perform a PPE doffing sequence, which will be video-recorded to allow for subsequent assessment. In the experimental group, participants will first undergo face-to-face training performed by third-year students using the Peyton 4-step approach before performing the doffing sequence themselves, which will also be video-recorded. All participants will then be asked to reconstruct the doffing sequence on an online platform. The recorded sequences will be assessed independently by two investigators: a prehospital emergency medicine expert and an infection prevention and control specialist. The assessors will be blinded to group allocation. Four to eight weeks after this first intervention, all participants will be asked to record the doffing sequence once again for a subsequent skill retention assessment and to reconstruct the sequence on the same online platform to assess knowledge retention. Finally, participants belonging to the control group will follow face-to-face training.

Results: The study protocol has been presented to the regional ethics committee (Req-2020-01340), which issued a declaration of no objection as such projects do not fall within the scope of the Swiss federal law on human research. Study sessions were performed in January and February 2021 in Geneva, and will be performed in April and June 2021 in Bern.

Conclusions: This study should help to determine whether face-to-face training using the Peyton 4-step approach improves the application and knowledge retention of a complex procedure when combined with an e-learning module. 
International Registered Report Identifier (IRRID): PRR1-10.2196/26927

(JMIR Res Protoc 2021;10(4):e26927) doi: 10.2196/26927

\section{KEYWORDS}

personal protective equipment; electronic learning; prehospital; student paramedics; infection prevention; face-to-face learning; protection; student; online learning; online education; protocol; randomized controlled trial; gamification

\section{Introduction}

\section{Background and Importance}

The emergence of COVID-19 has democratized the use of personal protective equipment (PPE) for all health care workers in and outside hospitals [1] in accordance with international recommendations [2]. Donning and doffing procedures contribute to the adequate use of PPE and reduce the risk of self-contamination of caregivers [3]. This last point is critical as frontline health care workers are a scarce and essential resource who are at increased risk of being contaminated [4].

Although the donning phase is associated with a low risk of contamination, doffing is a critical phase and greatly increases the risk of contamination of caregivers [5-9]. One of the strategies that effectively contributes to reducing staff self-contamination is doffing in structured areas dedicated to the removal of PPE [10,11]. However, this strategy is difficult to apply in the prehospital field, where health care workers must often doff PPE on site. It is therefore all the more relevant to train prehospital health care workers in the noncontaminating removal of PPE so that they can perform it adequately under all circumstances.

Two previous studies have shown that training prehospital staff in using PPE through a gamified electronic learning (e-learning) module increases the proportion of making an adequate choice of PPE [12,13]. However, this module failed to improve knowledge acquisition of correct doffing sequences. It was therefore concluded that e-learning training alone is insufficient to adequately train prehospital staff in the noncontaminating removal of PPE, and that other training modalities should be considered, either as standalone interventions or in combination with this module. The Peyton 4-step teaching approach [14] is an effective training structure that has been shown to increase knowledge and skill retention when compared to standard training in the acquisition of procedural skills [15]. Our hypothesis is that adding a face-to-face training modality using the Peyton 4-step approach to a gamified e-learning module could increase the proficiency of prehospital workers regarding this procedure, thus reducing the risk of contamination of prehospital staff [16].

\section{Objectives}

The primary aim of this study is to define whether the Peyton 4-step approach used in addition to our gamified e-learning module for teaching noncontaminant PPE removal increases the percentage of correct PPE doffing sequences performed by first-year paramedic students in comparison to e-learning alone.

\section{Methods}

\section{Study Design and Setting}

We will carry out a parallel-group, randomized, quadruple-blind (participants, instructors, outcome assessors, and data analyst) controlled superiority trial designed following the SPIRIT statement (see Multimedia Appendix 1 for the SPIRIT Checklist) [17], and including relevant elements from the CONSORT-EHEALTH checklist [18] and from the CHERRIES guidelines [19]. The design is detailed in Figure 1.

Figure 1. Study design.

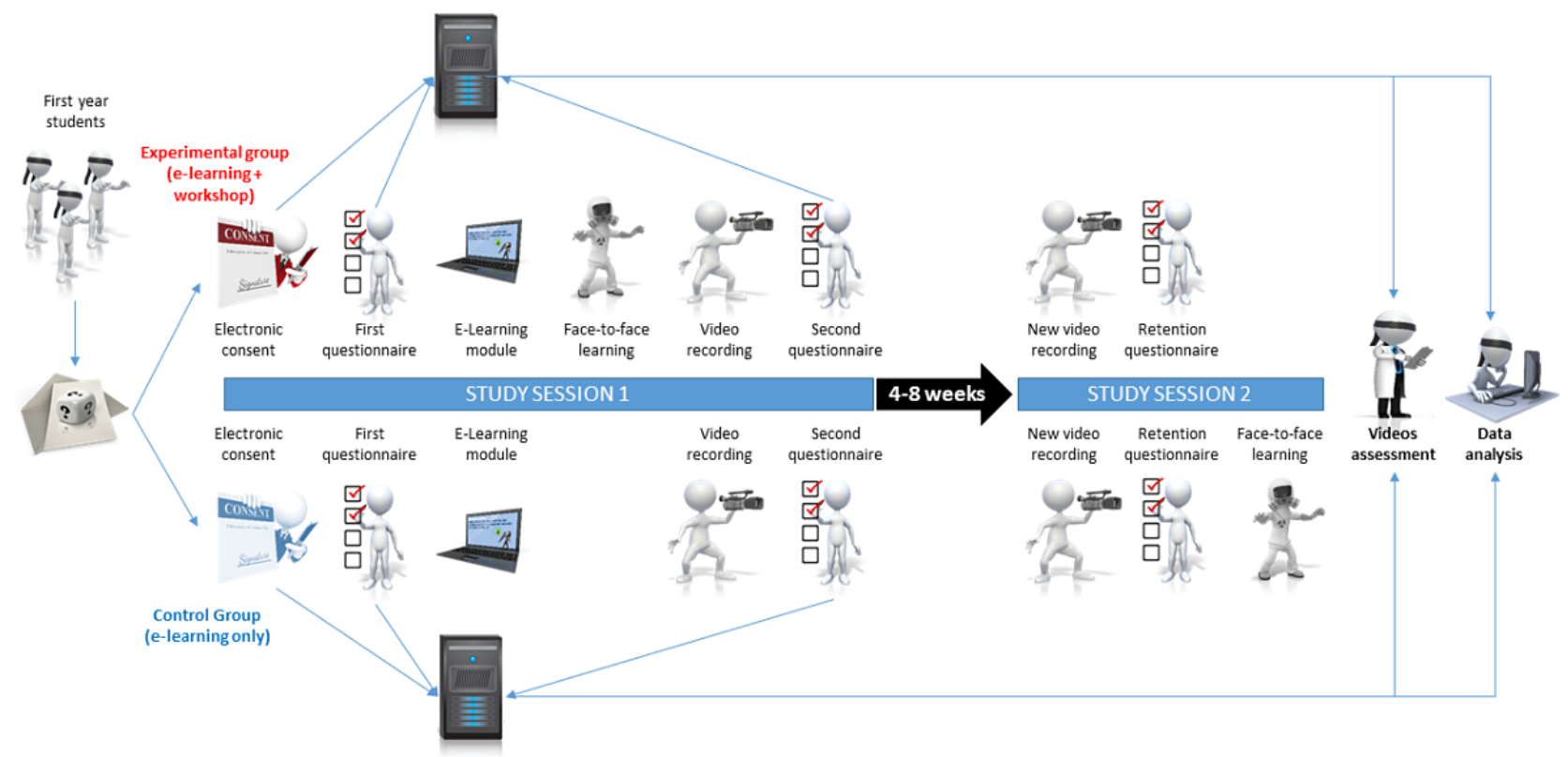


All first-year students $(\mathrm{N}=62)$ from the Colleges of Higher Education in Ambulance Care located in Geneva and Bern, Switzerland, will be invited to take part in this study. To allow the first-year German-speaking students to participate in the study, the study material, including the e-learning module, will be translated into German. Participation will be on a voluntary basis during their school time as part of their curriculum. There will be no exclusion criteria.

The instructors who will be recruited to take part in this study are third-year paramedic students. Their participation will be on a voluntary basis. They will be specifically trained by two investigators in the noncontaminating removal of PPE (LC) and the Peyton teaching approach (L Stuby). These investigators will be accompanied by a bilingual teacher from the Bernese school to help with potential language issues. Peer teaching or near-peer teaching has been shown to have a positive influence on peer learners and to permit a deeper approach to learning [20], with reduced levels of anxiety among participants [21]. The practicability of peer teaching and near-peer teaching has been assessed for different outcomes, including clinical skills $[22,23]$ or respiratory, cardiac, and blood physiology [24]. This form of teaching has recently been used in another study involving medical students [25]. It is therefore reasonable to extrapolate these results to our population of first-year student paramedics. Instructors will be informed that the objective is to teach the noncontaminating doffing of PPE to first-year students during two training sessions. They will not be aware of the study design and will therefore be blinded to the existence of two different training paths, and consequently to the allocation of participants and to the goals of the study. The instructors will receive a detailed PPE doffing procedure validated by infection prevention and control (IPC) experts (Multimedia Appendix 2) and a summary sheet of the Peyton approach steps (Multimedia Appendix 3). The instructor:learner ratio will range from $1: 1$ to $1: 3$ as such ratios have been shown to be particularly efficient [15].

\section{Online Platform}

An online platform [26] running under the Joomla! 3.9 content management system (Open Source Matters) will be developed by L Suppan for the purpose of this study. A survey component (Community Surveys Pro 5.5 CoreJoomla) will be installed on the platform. L Suppan will be the only author to have access to the platform's administration console. There will be no scheduled maintenance or update on the server during the study period. Once created, tested, and validated, the platform will not be altered before the end of the study period.

\section{Randomization and Concealment of Allocation}

An investigator (MS) who does not know the participants and will have no contact with them will randomly assign the participants into two groups according to a computer-generated list [27] with a 1:1 allocation ratio and stratification by school (Geneva, Bern French-speaking, and Bern German-speaking). Opaque, sealed envelopes containing individual login information will be created and given to local investigators. No one else will have access to the coding list. Given the complete lack of risk to the participants, there will be no unblinding procedure, no data monitoring, and no interim analysis. In addition, there is no need to elaborate plans regarding potential adverse events given the type of intervention and the design of this study.

Participants will be divided between the instructors randomly by one of the investigators (L Stuby or LC) using an online team generator [28].

\section{Enrollment and Consent}

Prior to the beginning of the study, students will be sent emails containing general information about the study (Multimedia Appendix 4). The home screen of the website will contain information regarding the study, including data security and the learning objectives (Figure 2 and Figure 3). Consent (including for the recording of videos) will be gathered electronically. Participants will be informed that they will attend, during the course of their learning path, a workshop on correct PPE doffing according to good practices validated by IPC experts.

Participation will be free and each participant will be able to withdraw at any time without giving any justification. Participants will benefit from this study by acquiring knowledge regarding the safe doffing of PPE, which will be useful in their practice. There will be no financial compensation or incentive.

The data collected are encoded using the randomly assigned connection identifiers; thus, if a participant keeps their identifiers, it will be possible for them to request that the answers be deleted once the survey is completed. 
Figure 2. French version of the platform welcome screen.

Bienvenue sur la page internet de l'étude/formation "Equipement de Protection Individuelle (EPI) - Contexte COVID-19".

Vous êtes maintenant sur le point de participer à une étude sur la formation des étudiant·e.s ambulanciers-ères au port des équipements de protection individuelle (EPI) utilisés dans le cadre de la pandémie de COVID-19. Vous allez participer à deux séances, au cours desquelles vous bénéficierez d’une formation e-learning ainsi que d'une formation présentielle.

Dans le cadre de cette étude, nous vous demanderons de renseigner des données personnelles, et nous réaliserons deux enregistrements vidéo de

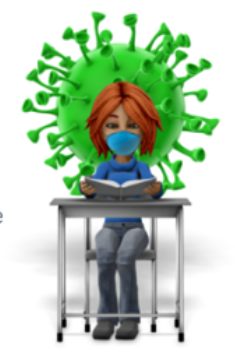
vous. Ces données seront stockées de manière sécurisée et anonyme et traitées de manière parfaitement confidentielle. Votre identité ne sera jamais révélée à des tiers. Elles seront utilisées uniquement dans le cadre de l'étude et dans un but de recherche et ne seront en aucun cas diffusées.

Vous pouvez en tout temps contacter les investigateurs rices de cette étude si vous avez des questions ou souhaitez des informations complémentaires. Vous êtes également libre de vous retirer de cette étude à tout moment en prenant contact avec ces mêmes personnes, dont les coordonnées se trouvent ci-dessous:

- Loric STUBY, I.stuby@gt-ambulances.ch

- Laurent SUPPAN, laurent.suppan@hcuge.ch

- Ludivine CURRAT, ludivine.crrt@eduge.ch

En vous connectant à ce site (à droite de votre écran), vous attestez avoir pris connaissance des informations précédentes concernant l'étude. Vous attestez également avoir compris que votre participation à cette étude est libre et volontaire, et que vous pouvez y mettre fin à tout moment sans que cela n'impacte la qualité de la formation que vous allez recevoir. Vous consentez également à l'utilisation de vos données personnelles ainsi que des enregistrements vidéo selon les modalités décrites précédemment.

\section{LOGIN}

\begin{tabular}{|l|}
\hline Identifiant \\
\hline Mot de passe \\
\hline
\end{tabular}

\section{$\square$ Se souvenir de moi}

Identifiant oublié ? Mot de passe oublié?

\section{Connexion}

Figure 3. German version of the platform welcome screen.

\section{WILIKOMMEN VERSION FRANCAISE}

Willkommen auf der Webseite der Studie / Ausbildung "Persönliche Schutzausrüstung (PSA) - COVID-19-Kontext".

Sie nehmen hiermit an einer Studie über das Tragen von persönlicher Schutzausrüstung (PSA) im Zusammenhang mit der COVID-19-Pandemie in Rahmen der Ausbildung von Rettungssanitätern teil. Es handelt sich dabei um zwei Sitzungen, in denen Sie sowohl von E-Learning-Ausbildung als auch von Präsenzausbildung profitieren.

Im Rahmen dieser Studie werden wir Sie bitten, persönliche Daten anzugeben und an zwei Videoaufnahmen teilzunehmen. Diese Daten werden sicher und anonym gespeichert und absolut vertraulich behandelt. Ihre Identität wird niemals an Dritte weitergegeben. Die Daten werden nur im Rahmen der Studie und zu Forschungszwecken verwendet und unter keinen Umständen freigegeben.

Sie können sich jederzeit an die Verantwortlichen dieser Studie wenden, wenn Sie Fragen haben oder zusätzliche Informationen benötigen. Sie können sich auch jederzeit von dieser Studie abmelden, indem Sie sich an eine Person der nachfolgenden Kontaktdaten wenden:

- Loric STUBY, I.stuby@gt-ambulances.ch

- Laurent SUPPAN, laurent.suppan@hcuge.ch

- Ludivine CURRAT, ludivine.crrt@eduge.ch

Durch das Einloggen auf der Webseite (rechts auf Ihrem Bildschirm), bestätigen Sie, dass Sie die vorherigen Informationen zu dieser Studie gelesen haben. Sie bestätigen auch, dass Ihre Teilnahme an dieser Studie freiwillig ist und dass Sie sie jederzeit beenden können, ohne damit Ihre Ausbildung zu beeinträchtigen. Sie sind weiter einverstanden, dass Ihre persönlichen Daten und die beiden Videoaufnahmen auf die oben beschriebene Weise verwendet werden.
LOGIN

Benutzername

Passwort

$\square$ Angemeldet bleiben

Benutzername vergessen?

Passwort vergessen?

Anmelden 


\section{Study Sequence}

After picking up an envelope, each participant will be asked to $\log$ into the platform with specific credentials. The welcome screen will be the same for both groups and, similar to the envelopes, will not contain any information regarding the study sequence to ensure that participants are adequately blinded.

After clicking the start button, a first questionnaire designed to collect demographic data will be displayed (Multimedia Appendix 5). Learning preferences (visual, aural, reading/writing, or kinesthetic [VARK]) will be assessed using the online VARK questionnaire, which will be displayed in the student's preferred idiom (either the French version translated by Johanne Barrette [29] or the German version translated by Greta Richter [30]), with permission from the original author (Heather Lander). This questionnaire consists of 16 multiple-choice items with four response options; possible scores range from 0 to 16 for each subscale. The VARK questionnaire has shown adequate validity and reliability [31]. Participants will access the VARK questionnaire by clicking on a link displayed on the online platform at the end of the first questionnaire; the results will be reported on a paper case report form (CRF; Multimedia Appendix 6) by one of the investigators before being entered directly on the study platform; a double check by the participant countersigning the document will be used to limit potential copy errors.

Both groups will then follow the e-learning module, the development of which has previously been described [32]. This module was initially developed in French and will be translated in German for the purpose of the study.

After completing the module, participants belonging to the control group will be asked to don the following PPE: protective glasses, FFP2 mask, coverall with hood, and gloves. They will then be asked to perform the doffing sequence individually, which will be recorded on video. After completing the doffing sequence, participants will be asked to go back to the online platform to electronically rebuild the doffing sequence.

Rather than immediately donning and doffing the PPE after completing the e-learning module, participants in the experimental group will be randomly allocated to the instructors to follow face-to-face learning according to the Peyton 4-step approach. After completing this workshop, these participants will resume the same path as their counterparts from the control group by moving on to the video recording of the doffing sequence and, finally, by being asked to rebuild the doffing sequence on the online platform.

Four to eight weeks later, depending on the schools' schedules, participants will be asked to take part in a second session. This time interval is sufficient to reliably assess retention, which has been shown to be nonlinear. Out of the proportion of participants who display a significant decline in knowledge retention at 3 months, half will already present a significant decline in knowledge retention after 4 weeks [33]. Both groups will first repeat the video recording of the PPE doffing sequence and then reconnect to the platform to reconstruct the doffing sequence by computer. The experimental group will then be considered as having completed the study path, while the control group will attend a face-to-face learning session (See SPIRIT diagram in Multimedia Appendix 7 and Figure 1).

\section{Face-to-Face Learning}

Face-to-face teaching will proceed according to the following steps based on the Peyton approach [14]: (1) the instructor will perform a complete doffing sequence in real time without any comments; (2) the instructor will perform a doffing sequence accompanied by step-by-step explanations (description of key points); (3) the learners will be asked to guide the instructor through the doffing sequence, step by step; (4) the learners will be asked to perform the complete doffing sequence before receiving individualized feedback. Each participant will perform this step only once.

Checklists and "buddy" systems have been used to improve the efficiency and security of doffing sequences [34,35]. Even though such techniques are undoubtedly useful, prehospital providers are required to perform PPE doffing procedures in many different locations, and sometimes lack access to either a "buddy" or even to a checklist. We therefore elected to refrain from giving any support document to the participants.

\section{Primary Outcome}

The primary outcome will be the proportion of doffing sequences correctly performed after knowledge acquisition. Since practices differ from one center to another, we have developed an assessment grid validated by an IPC specialist for the assessment of this outcome (Multimedia Appendix 8). The adequacy of the procedure will be blindly assessed individually by two investigators (a prehospital emergency medicine expert and an IPC specialist) viewing the videos recorded in three-quarter view and using the developed checklist. In case of disagreement, a consensus will be reached by discussion.

\section{Secondary Outcomes}

Seven secondary outcomes will be assessed: time required to teach the technique, time required to perform the doffing procedure, learner satisfaction, proportion of correct computer sequences, confidence in using PPE, and knowledge and skill retention.

The time required to teach the technique using the Peyton approach will be recorded on a paper CRF (Multimedia Appendix 9) by the instructor. Time will be measured from the beginning of step 1 until the last participant has completed the fourth and final step.

The time required to perform the doffing sequence will be recorded (in seconds) by analyzing the recording (measured from the moment the first item is taken off until the moment the learner announces that the procedure has been completed).

Learner satisfaction will be measured using a 5-point Likert scale (not satisfied at all, not satisfied, neutral/undetermined, satisfied, very satisfied).

Computerized doffing sequence accuracy involves reordering the presented sequence in random order in two steps: first in the contaminated zone and then in the noncontaminated zone. 
Confidence in the ability to use PPE will also be assessed using a 5-point Likert scale (not confident at all, not confident, neutral/undetermined, confident, very confident).

Knowledge retention will be assessed by reordering the computer sequence once again 4-8 weeks after the first acquisition intervention, whereas skill retention will be assessed in the same way as the primary outcome.

\section{Blinded Data Collection and Assessment}

Some outcomes will be recorded electronically. This will allow for their assessment to be independent from subjective human evaluation. For all other outcomes, assessors will be blinded to participant allocation.

Electronic data will be recorded and securely stored in an encrypted MariaDB database (Version 5.5.5; MariaDB Foundation) hosted on a Swiss server.

At the end of the study, all electronic data will be extracted to a comma-separated value file by the only investigator who will have access to the dataset (L Suppan). No personal data (name, first name, date of birth, or IP address) will be collected.

\section{Data Curation and Availability}

An investigator (LC) will assign specific codes to the videotaped sequences of each participant. These codes will be created by concatenating the identifier used by the participant to log into the platform and the session number. These codes will be the only information sent to the blinded assessors apart from the recordings. All paper CRFs, including completed video assessment grids, will be sent to the investigator in charge of randomization (MS) for the constitution of the database. All electronically recorded data will then be imported to create the final version of the database. All data that could allow a data analyst to identify the group allocation will be deleted. The groups will be renamed otherwise (groups "Plutello" and "Plutinson") and the curated database will be sent in Stata (Statacorp LLC) .dta file format to L Stuby for formal analysis. All investigators will be able to access the curated and coded dataset. The database will be deposited on Mendeley Data [36]. The videotapes will be used only for study purposes and destroyed once the curated data file has been created.

\section{Sample Size}

According to two previous studies [12,13], the percentage of correct doffing sequence compliance through the use of the e-learning module should be very low, as no participant was able to recreate the correct sequence on the online platform in either study. However, practical reality might be dissociated from the theoretical answers gathered on online platforms, making a control group necessary in this study. For the record, a recent observational study showed that $90 \%$ of the doffing sequences were incorrect [37].

We calculated that 46 participants would be needed to have a $90 \%$ chance of detecting, at the $5 \%$ significance level, an increase in the primary outcome from $10 \%$ in the control group to $50 \%$ in the experimental group; additional participants will be accepted as the training will be part of their curriculum.

\section{Statistical Analysis}

Data analysis will be performed using Stata 15.1. Owing to the small sample size, only nonparametric tests will be used. Fisher exact test will be used for dichotomous variables and the Mann-Whitney $U$ test will be used for continuous variables. The computerized doffing sequence accuracy will first be analyzed as a whole and then according to the respective doffing zones (contaminated and noncontaminated). This should help determine whether further teaching efforts should be concentrated on a particular part of the sequence. The Likert scales will be described graphically and then dichotomized for statistical analysis (satisfied versus not satisfied; confident versus not confident). The results will be described as a percentage with $95 \% \mathrm{CI}$ for the proportions and according to the median $(\mathrm{Q} 1-\mathrm{Q} 3)$ for the continuous variables. A $P$ value $<.05$ will be considered significant. A subgroup analysis by working status (actively working in an ambulance service or not) will be carried out as an increased rate in adequate choice of PPE has been shown in this subgroup [12]. Missing data will be excluded. There will be no adjustment or imputation.

\section{Results}

The study has been presented to our regional ethics committee (Req-2020-01340), which waived the need for further evaluation by issuing a declaration of "no objection" as such projects do not fall within the scope of the Swiss federal law on human research [38]. The study will be performed in accordance to the principles of the Declaration of Helsinki [39] and Good Clinical Practice guidelines [40]. A formal agreement has already been obtained from the schools' headmasters.

Once published, there will be no further modification to the study protocol. There is therefore no need to plan for communication of protocol amendments. This protocol version is 1.0 (January 11,2021 ).

The online platform was finalized on January 15, 2021 [26]. The platform was developed by L Suppan and will be thoroughly tested by three coauthors (L Stuby, LC, MS). The current version of the welcome screen, with detailed information for five aspects (learning objectives, right to refuse participation or to withdraw consent at any time, institutional affiliation, and contact information), is displayed in Figures 2 and 3.

Study sessions in Geneva were performed on January 25, 2021 for instructor formation, January 26, 2021 for the first session, and February 24, 2021 for the second session. Study sessions in Bern are scheduled for April 2021 for instructor formation and for the first sessions, and for June 2021 for the second sessions.

The results, whether positive or negative, will be submitted for publication. They will be reported according to the CONSORT-EHEALTH checklist [18]. Relevant elements from the CHERRIES guidelines [19] will also be incorporated in the report. 


\section{Discussion}

\section{Main Considerations}

This study should help determine whether face-to-face training using the Peyton 4-step approach in addition to the e-learning module can improve the application of a doffing procedure created by IPC specialists. It should also determine whether this approach improves knowledge and skill retention.

Four learning preference modalities have been previously described [41]: visual, which includes the depiction of information in diagrams, maps, graphs, arrows, circles, hierarchies, and other devices, that people use to represent what could have been presented in words; aural/auditory, which describes a preference for information that is "heard or spoken"; reading/writing, which describes preferences for information displayed as words; and kinesthetic, which refers to the "perceptual preference related to the use of experience and practice (simulated or real)." Although the e-learning module alone might suit the learning preferences of two of the four categories (visual and reading/writing) and face-to-face training may preferentially suit the visual, auditory, and kinesthetic categories, the combination of an e-learning module with face-to-face learning should theoretically suit all four categories.

Concerning our target population, assessment with first-year students who are new to the field and who have not yet been exposed to PPE use will allow us to test our hypothesis on learners who are still naive regarding the doffing method. These students should not be prejudiced and should not have developed any particular habit, good or bad, regarding the use of PPE.

One of the strengths of our study is that the videotapes will be independently assessed by an IPC expert and a prehospital emergency medicine expert.

We chose to design this study to assess the impact of face-to-face learning added to the e-learning module. Another interesting design would be to assess the gain of adding the e-learning module to face-to-face learning with the control group following the face-to-face learning alone and to the experimental group following the face-to-face learning and e-learning module. Although we considered creating a third group to test this hypothesis, we finally decided on the use of two groups given the limited sample size.

\section{Limitations}

Some limitations can already be anticipated. First, the specific population of the sample may limit the generalizability of the results.

Second, using third-year students as instructors allows us to blind instructors, but can limit the quality of teaching. Indeed, these students who will be trained as an instructor within the framework of the study have no expertise in either IPC or in teaching, and have no or little experience in their profession and as an instructor. When peer students or student tutors are used as teachers, the effectiveness of the Peyton teaching approach is less clear [15].

The aim is to teach the technique for the first time, and therefore it will not be integrated in a care simulation and will be performed in a classroom setting. Therefore, the environment will not be representative of the actual situations in which the participants will have to perform these actions. This implies that the mental load on the learners will be lower than when they will have to apply these techniques in the field or integrated into simulations. Therefore, it could be beneficial, after learning the procedure, to train for actual application during simulated care situations.

\section{Conclusion}

This study should help to determine whether face-to-face training in addition to an e-learning module can improve the application of a complex procedure and enhance its retention.

\section{Acknowledgments}

This study is supported by a grant from the Hans Wilsdorf Foundation for the payment of publications fees. Material costs (coveralls, FFP2 masks) will be paid by the Colleges of Higher Education in Ambulance Care. These funding sources had no role in the design of this study, and will not have any role during its execution, analyses, interpretation of the data, or decision to submit results. The authors would like to thank Emmanuel Daniel, specialist nurse from the Infection Prevention and Control Division, Geneva University Hospital, for the validation of the steps (Multimedia Appendices 2 and 8); Mohamed Abbas for his wise advice; Céline Arm, secretary from the Center for Medical Education in Bern, for the text translation of the e-learning module; Franco Riva and Yves Meury, school headmasters who provided agreement for the study; and Heather Lander who gave authorization for use of both the French and German versions of the VARK questionnaire (Copyright Version 8.01, 2019, held by VARK Learn Limited, Christchurch, New Zealand).

\section{Authors' Contributions}

LC initiated the study design. L Stuby conceived of the study and wrote the first draft of the present protocol. MS and L Suppan helped with implementation. MS, L Suppan, BG, and SH provided expertise in clinical trial design. SH provided expertise in the IPC domain. LC and MM are the local study coordinators. L Stuby will perform the primary statistical analysis. All authors critically revised the manuscript, contributed to the refinement of the study protocol, and approved the final manuscript. 


\section{Conflicts of Interest}

L Stuby has received financial compensation when serving as an external teaching professional or exam expert for the Colleges of Higher Education in Ambulance Care in Geneva and Bern. MM is employed by the Center for Medical Education in Bern as a teacher. The other authors have no conflicts of interest to declare.

\section{Multimedia Appendix 1}

SPIRIT checklist.

[DOCX File, 48 KB-Multimedia Appendix 1]

\section{Multimedia Appendix 2}

PPE doffing procedure for instructors.

[DOCX File, 28 KB-Multimedia Appendix 2]

\section{Multimedia Appendix 3}

Peyton approach stages reminder sheet for instructors.

[DOCX File, 27 KB-Multimedia Appendix 3]

\section{Multimedia Appendix 4}

Copy of email to participants.

[DOCX File, 16 KB-Multimedia Appendix 4]

\section{Multimedia Appendix 5}

Questionnaire 1: demographic data.

[DOCX File , 27 KB-Multimedia Appendix 5]

\section{Multimedia Appendix 6}

VARK paper case report form (CRF).

[DOCX File, 27 KB-Multimedia Appendix 6]

\section{Multimedia Appendix 7}

SPIRIT diagram. Timeline of enrollment, interventions, and assessments.

[DOCX File, 19 KB-Multimedia Appendix 7]

\section{Multimedia Appendix 8}

Assessment grid.

[DOCX File, 28 KB-Multimedia Appendix 8]

\section{Multimedia Appendix 9}

Instructors paper case report form (CRF).

[DOCX File, 26 KB-Multimedia Appendix 9]

\section{References}

1. Abbas M, Robalo Nunes T, Martischang R, Zingg W, Iten A, Pittet D, et al. Nosocomial transmission and outbreaks of coronavirus disease 2019: the need to protect both patients and healthcare workers. Antimicrob Resist Infect Control 2021 Jan 06;10(1):7 [FREE Full text] [doi: 10.1186/s13756-020-00875-7] [Medline: 33407833]

2. Rational use of personal protective equipment for coronavirus disease (COVID-19) and considerations during severe shortages. World Health Organization. URL: https://www.who.int/publications-detail-redirect/ rational-use-of-personal-protective-equipment-for-coronavirus-disease-(covid-19)-and-considerations-during-severe-shortages [accessed 2020-11-24]

3. Verbeek JH, Rajamaki B, Ijaz S, Sauni R, Toomey E, Blackwood B, et al. Personal protective equipment for preventing highly infectious diseases due to exposure to contaminated body fluids in healthcare staff. Cochrane Database Syst Rev 2020 Apr 15;4:CD011621 [FREE Full text] [doi: 10.1002/14651858.CD011621.pub4] [Medline: 32293717] 
4. Nguyen LH, Drew DA, Graham MS, Joshi AD, Guo C, Ma W, et al. Risk of COVID-19 among front-line health-care workers and the general community: a prospective cohort study. Lancet Public Health 2020 Sep;5(9):e475-e483. [doi: $10.1016 /$ S2468-2667(20)30164-X]

5. Tomas ME, Kundrapu S, Thota P, Sunkesula VCK, Cadnum JL, Mana TSC, et al. Contamination of health care personnel during removal of personal protective equipment. JAMA Intern Med 2015 Dec;175(12):1904-1910. [doi: 10.1001/jamainternmed.2015.4535] [Medline: 26457544]

6. Mulvey D, Mayer J, Visnovsky L, Samore M, Drews F. Frequent and unexpected deviations from personal protective equipment guidelines increase contamination risks. Am J Infect Control 2019 Sep;47(9):1146-1147. [doi: 10.1016/j.ajic.2019.03.013] [Medline: $\underline{\text { 31027940] }}$

7. Okamoto K, Rhee Y, Schoeny M, Lolans K, Cheng J, Reddy S, Centers for Disease Control and Prevention Epicenters Program. Impact of doffing errors on healthcare worker self-contamination when caring for patients on contact precautions. Infect Control Hosp Epidemiol 2019 May;40(5):559-565. [doi: 10.1017/ice.2019.33] [Medline: 30890193]

8. Lim SM, Cha WC, Chae MK, Jo IJ. Contamination during doffing of personal protective equipment by healthcare providers. Clin Exp Emerg Med 2015 Sep;2(3):162-167. [doi: 10.15441/ceem.15.019] [Medline: 27752591]

9. Suen LKP, Guo YP, Tong DWK, Leung PHM, Lung D, Ng MSP, et al. Self-contamination during doffing of personal protective equipment by healthcare workers to prevent Ebola transmission. Antimicrob Resist Infect Control 2018 Dec 22;7(1):157 [FREE Full text] [doi: 10.1186/s13756-018-0433-y] [Medline: 30607244]

10. Saran S, Gurjar M, Garg A. Identifying and implementing strategies to reduce the risk of self-contamination of health care workers caused by doffing of personal protective equipment during the COVID-19 pandemic. Disaster Med Public Health Prep 2020 Oct 22:1-4 [FREE Full text] [doi: 10.1017/dmp.2020.396] [Medline: 33087198]

11. Wundavalli L, Singh S, Singh AR, Satpathy S. How to rapidly design and operationalise PPE donning and doffing areas for a COVID-19 care facility: quality improvement initiative. BMJ Open Qual 2020 Sep;9(3):e001022 [FREE Full text] [doi: 10.1136/bmjoq-2020-001022] [Medline: 32978176]

12. Suppan L, Stuby L, Gartner B, Larribau R, Iten A, Abbas M, et al. Impact of an e-learning module on personal protective equipment knowledge in student paramedics: a randomized controlled trial. Antimicrob Resist Infect Control 2020 Nov 10;9(1):185 [FREE Full text] [doi: 10.1186/s13756-020-00849-9] [Medline: 33168097]

13. Suppan L, Abbas M, Stuby L, Cottet P, Larribau R, Golay E, et al. Effect of an e-learning module on personal protective equipment proficiency among prehospital personnel: web-based randomized controlled trial. J Med Internet Res 2020 Aug 21;22(8):e21265 [FREE Full text] [doi: 10.2196/21265] [Medline: 32747329]

14. Peyton JWR. Teaching \& learning in medical practice. Heronsgate Rickmansworth, Herts, UK: Manticore Europe Ltd; 1998:978-971.

15. Giacomino K, Caliesch R, Sattelmayer KM. The effectiveness of the Peyton's 4-step teaching approach on skill acquisition of procedures in health professions education: A systematic review and meta-analysis with integrated meta-regression. PeerJ 2020;8:e10129. [doi: 10.7717/peerj.10129] [Medline: 33083149]

16. Díaz-Guio DA, Ricardo-Zapata A, Ospina-Velez J, Gómez-Candamil G, Mora-Martinez S, Rodriguez-Morales AJ. Cognitive load and performance of health care professionals in donning and doffing PPE before and after a simulation-based educational intervention and its implications during the COVID-19 pandemic for biosafety. Infez Med 2020 Jun 01;28(Suppl 1):111-117 [FREE Full text] [Medline: 32532947]

17. Chan A, Tetzlaff JM, Altman DG, Laupacis A, Gøtzsche PC, Krleža-Jerić K, et al. SPIRIT 2013 statement: defining standard protocol items for clinical trials. Ann Intern Med 2013 Feb 05;158(3):200-207 [FREE Full text] [doi:

10.7326/0003-4819-158-3-201302050-00583] [Medline: 23295957]

18. Eysenbach G, CONSORT-EHEALTH Group. CONSORT-EHEALTH: improving and standardizing evaluation reports of web-based and mobile health interventions. J Med Internet Res 2011 Dec 31;13(4):e126 [FREE Full text] [doi: 10.2196/jmir.1923] [Medline: 22209829]

19. Eysenbach G. Improving the quality of web surveys: the Checklist for Reporting Results of Internet E-Surveys (CHERRIES). J Med Internet Res 2004 Sep 29;6(3):e34 [FREE Full text] [doi: 10.2196/jmir.6.3.e34] [Medline: 15471760]

20. Agius A, Calleja N, Camenzuli C, Sultana R, Pullicino R, Zammit C, et al. Perceptions of first-year medical students towards learning anatomy using cadaveric specimens through peer teaching. Anat Sci Educ 2018 Jul;11(4):346-357. [doi: 10.1002/ase.1751] [Medline: 29112798]

21. McKenna L, French J. A step ahead: teaching undergraduate students to be peer teachers. Nurse Educ Pract 2011 Mar;11(2):141-145. [doi: 10.1016/j.nepr.2010.10.003] [Medline: 21051284]

22. Weyrich P, Schrauth M, Kraus B, Habermehl D, Netzhammer N, Zipfel S, et al. Undergraduate technical skills training guided by student tutors--analysis of tutors' attitudes, tutees' acceptance and learning progress in an innovative teaching model. BMC Med Educ 2008 Apr 09;8(1):18-19 [FREE Full text] [doi: 10.1186/1472-6920-8-18] [Medline: 18400106]

23. Mutwali IM, Hassan AN. Skills training of junior medical students: Can peer teaching be the solution? Afr J Health Prof Educ 2013 Oct 28;5(2):84. [doi: 10.7196/ajhpe.235]

24. Jackson TA, Evans DJR. Can medical students teach? A near-peer-led teaching program for year 1 students. Adv Physiol Educ 2012 Sep;36(3):192-196. [doi: 10.1152/advan.00035.2012] [Medline: 22952257] 
25. Suppan L, Herren T, Taramarcaz V, Regard S, Martin-Achard S, Zamberg I, et al. A short intervention followed by an interactive e-learning module to motivate medical students to enlist as first responders: protocol for a prospective implementation study. JMIR Res Protoc 2020 Nov 06;9(11):e24664 [FREE Full text] [doi: 10.2196/24664] [Medline: 33155574]

26. Suppan L, Suppan M, Currat L, Stuby L. "Equipement de Protection Individuelle (EPI) - Contexte COVID-19" study platform. 2021 Jan 15. URL: https://covid-ppe.anesth.ch/fr/ [accessed 2021-01-15]

27. Online Randomisation List Generator. URL: https://www.sealedenvelope.com/simple-randomiser/v1/lists [accessed 2020-11-24]

28. Random Lists. Random Team Generator. URL: https://www.randomlists.com/team-generator [accessed 2020-11-24]

29. VARK questionnaire. VARK Learn Ltd. URL: https://vark-learn.com/le-questionnaire-vark/ [accessed 2020-11-24]

30. VARK - Guide Learn Styles. Der VARK-Fragebogen. URL: https://vark-learn.com/der-vark-fragebogen/ [accessed 2020-11-24]

31. Leite WL, Svinicki M, Shi Y. Attempted validation of the scores of the VARK: learning styles inventory with multitrait-multimethod confirmatory factor analysis models. Educ Psychol Meas 2009 Aug 31;70(2):323-339. [doi: $10.1177 / 0013164409344507]$

32. Suppan M, Gartner B, Golay E, Stuby L, White M, Cottet P, et al. Teaching adequate prehospital use of personal protective equipment during the COVID-19 pandemic: development of a gamified e-learning module. JMIR Serious Games 2020 Jun 12;8(2):e20173 [FREE Full text] [doi: 10.2196/20173] [Medline: $\underline{32516115]}$

33. Kamuche FU, Ledman RE. Relationship of Time and Learning Retention. J Coll Teach Learn 2005 Aug 01;2(8):25-28. [doi: $10.19030 /$ tlc.v2i8.1851]

34. Mumma JM, Durso FT, Casanova LM, Erukunuakpor K, Kraft CS, Ray SM, et al. Common behaviors and faults when doffing personal protective equipment for patients with serious communicable diseases. Clin Infect Dis 2019 Sep 13;69(Suppl 3):S214-S220 [FREE Full text] [doi: 10.1093/cid/ciz614] [Medline: 31517977]

35. Parush A, Wacht O, Gomes R, Frenkel A. Human factor considerations in using personal protective equipment in the COVID-19 pandemic context: binational survey study. J Med Internet Res 2020 Jun 17;22(6):e19947 [FREE Full text] [doi: 10.2196/19947] [Medline: 32511099]

36. Mendeley Data. URL: https://data.mendeley.com/ [accessed 2020-11-24]

37. Phan LT, Maita D, Mortiz DC, Weber R, Fritzen-Pedicini C, Bleasdale SC, CDC Prevention Epicenters Program. Personal protective equipment doffing practices of healthcare workers. J Occup Environ Hyg 2019 Aug 10;16(8):575-581 [FREE Full text] [doi: 10.1080/15459624.2019.1628350] [Medline: $\underline{\text { 31291152] }}$

38. Swiss ConfederationSR 810.30 Federal Act of 30 September 2011 on Research involving Human Beings (Human Research Act, HRA). Fedlex. URL: https://www.admin.ch/opc/en/classified-compilation/20061313/index.html [accessed 2020-11-24]

39. World Medical Association. World Medical Association Declaration of Helsinki: ethical principles for medical research involving human subjects. JAMA 2013 Nov 27;310(20):2191-2194. [doi: 10.1001/jama.2013.281053] [Medline: 24141714]

40. E6 Good Clinical Practice. International Council for Harmonisation of Technical Requirements for Pharmaceuticals for Human Use (ICH). 1996. URL: https://www.ich.org/page/efficacy-guidelines [accessed 2020-11-24]

41. Fleming N, Mills C. Not another inventory, rather a catalyst for reflection. Improve Acad 1992;11(1):137-155. [doi: 10.1002/j.2334-4822.1992.tb00213.x]

\section{Abbreviations \\ CRF: case report form \\ e-learning: electronic learning \\ IPC: infection prevention and control \\ PPE: personal protective equipment \\ VARK: visual, aural, reading/writing, or kinesthetic}

Edited by G Eysenbach; submitted 11.01.21; peer-reviewed by K Wiley; comments to author 01.02.21; revised version received
01.02.21; accepted 08.04.21; published 30.04.21
Please cite as:
Stuby L, Currat L, Gartner B, Mayoraz M, Harbarth S, Suppan L, Suppan M
Impact of Face-to-Face Teaching in Addition to Electronic Learning on Personal Protective Equipment Doffing Proficiency in Student
Paramedics: Protocol for a Randomized Controlled Trial
JMIR Res Protoc 2021;10(4):e26927
URL: https://www.researchprotocols.org/2021/4/e26927
doi: $10.2196 / 26927$
PMID:


CLoric Stuby, Ludivine Currat, Birgit Gartner, Mathieu Mayoraz, Stephan Harbarth, Laurent Suppan, Mélanie Suppan. Originally published in JMIR Research Protocols (https://www.researchprotocols.org), 30.04.2021. This is an open-access article distributed under the terms of the Creative Commons Attribution License (https://creativecommons.org/licenses/by/4.0/), which permits unrestricted use, distribution, and reproduction in any medium, provided the original work, first published in JMIR Research Protocols, is properly cited. The complete bibliographic information, a link to the original publication on https://www.researchprotocols.org, as well as this copyright and license information must be included. 